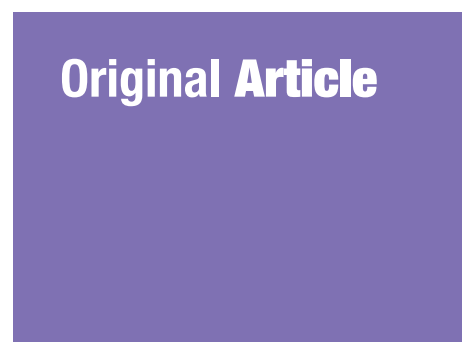

Submitted: 9 Oct 2020

Accepted: 20 Mar 2021

Online: 26 Aug 2021

\section{Prevalence, Pattern and Predictors of Child Sexual Abuse Among Senior Secondary School Students in Enugu Metropolis}

\author{
Onyinye Hope ChImE ${ }^{1,2}$, Chinonyelu Jennie ORJI ${ }^{1,2}$, \\ Tonna Jideofor ANEKE ${ }^{1}$, ljeoma Ngozi NwOKE ${ }^{1}$
}

\author{
1 Department of Community Medicine, Enugu State University Teaching \\ Hospital, Enugu State, Nigeria \\ 2 Department of Community Medicine, Enugu State University College of \\ Medicine, Enugu State, Nigeria
}

To cite this article: Chime OH, Orji CJ, Aneke TJ, Nwoke IN. Prevalence, pattern and predictors of child sexual abuse among senior secondary school students in Enugu Metropolis. Malays J Med Sci. 2021;28(4):123-137. https://doi.org/10.21315/mjms2021.28.4.13

To link to this article: https://doi.org/10.21315/mjms2021.28.4.13

\begin{abstract}
Objective: Child sexual abuse (CSA) is a growing public health concern with health, academic and psychosocial implications. The aim of this study was to determine the prevalence, pattern and predictors of CSA among secondary school students.

Methods: This was a cross-sectional study carried out among adolescents in four secondary schools in Enugu Metropolis, Nigeria. A pretested self-administered questionnaire was used to collect information from 325 adolescents and data was analysed with a significance level set at $P \leq 0.05$.

Results: The prevalence of CSA in this study was 116 (35.7\%). While the majority 20 (40\%) of the victims were forced to watch pornography, most of the perpetrators were neighbours 34 (29.3\%). A higher proportion of the victims were abused once, 79 (68.1\%); when they were between 12 and 18 years old, 62 (53.4\%); and at home, 39 (33.6\%). Grouped ages, whom the child lived with, father's and mother's education, and father's occupation were statistically significant on bivariate analysis. Predictors of CSA were students in senior secondary school Class 2 (SSS2) and those whose fathers were employed.

Conclusion: Our study revealed a high prevalence of CSA. Comprehensive sexuality education and legislative policies should be implemented to educate adolescents and deter perpetrators.
\end{abstract}

Keywords: child, child abuse, sexual, prevalence, students, schools

\section{Introduction}

The World Health Organization (WHO) defines child sexual abuse (CSA) as 'the involvement of a CSA that he or she does not fully comprehend, is unable to give informed consent to, or for which the child is not developmentally prepared and cannot give consent or that violates the laws or social taboos of society. CSA is evidenced by the activity between a child and an adult or another child and who by age or development is in a relationship of responsibility, trust or power, the activity being intended to gratify or satisfy the needs of the other person. This may include but is not limited to the inducement or coercion of a child to engage in any unlawful sexual activity; the exploitative use of a child in prostitution or other unlawful sexual practices; the exploitative use of children in pornographic performances and materials' (1). This includes sexual behaviour such as touching of the breasts, buttocks and genitals, whether the victim is dressed or undressed, fellatio, cunnilingus and penetration 
of the vagina or anus with sexual organs or with objects as well as watching of pornographic photography $(2,3)$.

According to the WHO, adolescents are defined as young people between the ages of 10 and 19 years old (4). At this age, they have limited knowledge about the natural processes of puberty, sexual health, pregnancy or reproduction (5). It is known to be the time for rapid development of knowledge and skills, learning to manage emotions, relationships, acquire attributes and abilities that will be necessary for enjoying the adolescent years and assuming adult roles (6). Globally, adolescents are particularly vulnerable and contribute to a third of all new cases of human immunodeficiency virus (HIV) infections, high levels of violence, early marriage and low school attendance rate and enrollment than primary school children (7-9). During this period, they suddenly become aware of the tremendous changes that are taking place in their sex organs and begin to seek various avenues to get answers to their sexual interest $(7-10)$.

Worldwide, people are gradually realising that the closed nature of school environments and their absence of accountability systems can predispose adolescents to sexual abuse especially in Africa $(10,11)$. A study done in Nigeria showed that majority of the perpetrators were friends, neighbours and family members (12). Most perpetrators of sexual abuse are usually males and are known to their victims (13). A study done in the United States of America documented that for every $2 \mathrm{~min}$, an adolescent is sexually assaulted and on the average over 237,868 victims are sexually assaulted each year (14).

CSA is becoming a social and public health concern especially because of its short- and longterm effects $(9,15)$. These include transmission of HIV and other sexually transmitted infections (STIs), somatic and visceral injuries, unwanted pregnancy, obstructed labour, vesico-vaginal and recto-vaginal fistula (16). They are also associated with high-risk behaviour such as multiple sexual partners, prostitution, delinquency in later life, substance abuse and psychological problems like feeling of vulnerability, fear, shame, guilt, poor self-esteem and depression (17-19).

The prevalence of CSA globally is $18 \%$ for girls and $7.6 \%$ for boys (20). According to WHO, 1 in every 13 men and 1 in every 5 females suffered various forms of sexual violence during childhood (21). The worldwide prevalence of
CSA ranges from $5 \%$ to $36 \%(20,22)$. The highest prevalence of CSA is in Africa (34.4\%) followed by Asia and Oceania (23.9\%), then Europe (9.2\%) (20). The true burden of CSA in Nigeria is unknown and is estimated to vary between $5 \%$ and $38 \%$ across different parts of the country (23-25). Due to cultural diversities, weak child protection, legal and health-care systems, the exact prevalence rates of CSA in Nigeria may be difficult to evaluate as the crime is usually covered up and never reported $(9,15)$. Survivors of CSA usually display a more self-destructive attitude and experience more suicidal ideation than those who have not been abused (15). Irrespective of the adoption of the Child's Right Act by Nigeria in 2003, which protects children against sexual abuse and exploitation, it remains a crime that does not only occur in Nigeria but also all around the world in different settings across various socioeconomic backgrounds and is punishable under the law (26-27).

The aim of this study was to determine the prevalence, pattern and predictors of CSA among secondary school children in Enugu Metropolis. This will throw light on CSA in secondary schools in Enugu, Nigeria so as to help affected parents and children cope with the management and prevention of this social problem (16). This study will also help government to inform policy formulations and design interventions to reduce the burden of CSA in Enugu Metropolis (16).

\section{Methods}

\section{Study Area}

Enugu Metropolis is the capital of Enugu State, Nigeria (28). It comprises Enugu South, Enugu North and Enugu East Local Government Area (29). It has a population of 722,664 as at the 2006 census (28). It is mainly populated by immigrants especially rural-urban migrants and this urban town lies about 221 metre to 317 metre above mean sea level. (28) There are about 28 public secondary schools spread across the city (29).

\section{Study Design and Population}

This was a cross-sectional descriptive study. About 325 adolescents were included in the study which was carried out between April and June 2019. Senior secondary school students (Grades 1-3) attending public secondary schools registered with the Enugu State Ministry of 
Education were included in the study. This particular group of students were chosen because they are considered to be mature enough to talk about their sexual abuse experiences. However, the senior secondary school system in Nigeria comprises mostly of middle and late adolescents and they make up majority of our study population (15). The schools are the New Haven Secondary School, the Federal Government College, the Model High Secondary School Amaechi Awkunanaw and the Army Day Secondary School in Enugu State, Nigeria.

\section{Sample Size Determination}

The minimum sample size was calculated using Fischer's formula (30). The prevalence of CSA for this study was calculated from the prevalence obtained from a previous populationbased study conducted in Enugu State University Teaching Hospital Parklane, Enugu (31). Using the Fischer's formula of $N=Z^{2} \times P Q / d^{2}$ where $N=$ sample size, $Z=$ confidence interval at 95\% level of significance as $1.96, P=$ reference prevalent rate (this was $8.8 \%$ ), $d=$ precision rate (0.05), we obtained a sample size of 123 and when a $10 \%$ non-response rate was added, the minimum sample size came up to 136 . However, we chose to increase this sample size significantly to make our study robust.

\section{Sampling Procedure}

A multi-stage sampling technique was used for this study. The list of registered secondary schools in the Enugu Metropolis was obtained from the Enugu State Ministry of Education. There are 13 public schools in the metropolis, five in Enugu South Local Government Area (LGA) and four each in Enugu North and Enugu South LGAs. The four schools recruited into the study were proportionally selected from the three LGAs in the metropolis [Enugu South LGA (Model High Secondary School Amaechi and Army Day Secondary School), Enugu East LGA (New Haven Secondary School) and Enugu North LGA (Federal Government College)]. The sampling frame was obtained from the register of senior secondary school students in the chosen schools. The next step involved a proportional allocation of the population of these students from each class in each of the selected schools. A systematic sampling method was then used in the selection of the students. Students were recruited consecutively until the sample size was obtained.

\section{Data Collection and Analysis}

Information was collected using a pretested self-administered questionnaire which was designed from previous studies. These questions were validated by professionals working with sexually abused children like clinicians, police officers and social workers by including all the questions that were considered relevant and appropriate for this subject. Confusing questions were discarded upon advice by the expert reviewers. It was written in English language as this was the medium of instruction in all institutions of learning in Nigeria. The questions were grouped under different sections to elicit information on sociodemographics, prevalence and pattern of CSA. This was distributed to the participants and collection was made on the same day by the researcher. Information was collected from April to June 2019.

Data was analysed using Statistical Package for the Social Sciences version 22 software. Data analysis was presented in tables. Bivariate analysis was used in testing for the associations between CSA and sociodemographic characteristics. Furthermore, multivariate analysis was used to determine the predictors of CSA with the level of significance set at $P \leq 0.2$.

\section{Ethical Clearance}

Ethical approval was obtained from the Health Research and Ethics Committee of Enugu State University Teaching Hospital. A formal permission was requested and granted through the Commissioner of Education and Principals of each school. Signed consent and assent were obtained from parents/guardians of the respondents and the respondents themselves respectively. To maintain confidentiality of the respondents, serial numbers were used for identification instead of names; the questionnaires were kept safe properly and made easily obtainable to the researchers only. The researchers themselves described the purpose of the study to the respondents and were allowed to ask questions concerning the research before embarking on completion of the questionnaire (32). The researchers also explained to them that the study was risk free, however respondents who felt uncomfortable during the study were advised that they could withdraw at any point in time and directed to the school counselor for counseling. 


\section{Results}

Table 1 shows that out of 325 respondents, majority 230 (70.8\%) were aged between 15 and 17 years old, 178 (54.8\%) were females, most were from the Igbo tribe 306 (94.2\%) and from senior secondary school Class 2 (SSS2) 187 (57.5\%). More than half of the respondents were living with their parents 219 (67.3\%). Secondary school education was the highest academic level achieved by of the fathers 263 (81.0\%) and mothers 264 (82.2\%).
Figure 1 highlights the general prevalence of CSA among the respondents as 116 (35.7\%).

Table 2 illustrates that out of a total of 116 respondents, 50 was for CSA without physical contact with majority of the group belonging to been forced to watch pornography 20 (40\%). For those that were sexually abused with physical contact but without penetration, out of 45 respondents, 10 (22.2\%) of them experienced been touched against will with sexual intentions and forced vaginal sexual intercourse against will but the abuser did not succeed. Out of a

Table 1. Sociodemographic characteristics of the respondents

\begin{tabular}{|c|c|c|}
\hline Variables & Descriptions & $N(\%)$ \\
\hline \multirow[t]{3}{*}{ Age (years) } & $11-13$ & $28(8.6)$ \\
\hline & $14-16$ & $230(70.8)$ \\
\hline & $17-19$ & $67(20.6)$ \\
\hline \multirow[t]{2}{*}{ Gender } & Male & $147(45.2)$ \\
\hline & Female & $178(54.8)$ \\
\hline \multirow[t]{3}{*}{ Class } & SSS1 & $86(26.5)$ \\
\hline & SSS2 & $187(57.5)$ \\
\hline & $\mathrm{SSS}_{3}$ & $52(16.0)$ \\
\hline \multirow[t]{2}{*}{ Tribe } & Igbo & $306(94.2)$ \\
\hline & Others & $19(5.8)$ \\
\hline \multirow[t]{4}{*}{ Who do you live with } & Both parents & $219(67.3)$ \\
\hline & One parent & $46(14.2)$ \\
\hline & Relatives & $40(12.3)$ \\
\hline & Non-relatives & $20(6.2)$ \\
\hline \multirow[t]{2}{*}{ Mother's education level } & Primary education and below & $58(17.8)$ \\
\hline & Secondary education and above & $264(82.2)$ \\
\hline \multirow[t]{2}{*}{ Father's education level } & Primary education and below & $62(19.0)$ \\
\hline & Secondary education and above & $263(81.0)$ \\
\hline \multirow[t]{5}{*}{ Mother's occupation } & Unemployed & $13(4.0)$ \\
\hline & Student & $13(4.0)$ \\
\hline & Self-employed & $177(54.5)$ \\
\hline & Salary-employed & $117(36.0)$ \\
\hline & Retired & $5(1.5)$ \\
\hline \multirow[t]{5}{*}{ Father's occupation } & Unemployed & $15(4.6)$ \\
\hline & Student & $16(4.9)$ \\
\hline & Self-employed & $160(49.2)$ \\
\hline & Salary-employed & $110(33.9)$ \\
\hline & Retired & $24(7.4)$ \\
\hline
\end{tabular}


Original Article | Predictors of child sexual abuse in Enugu, Nigeria

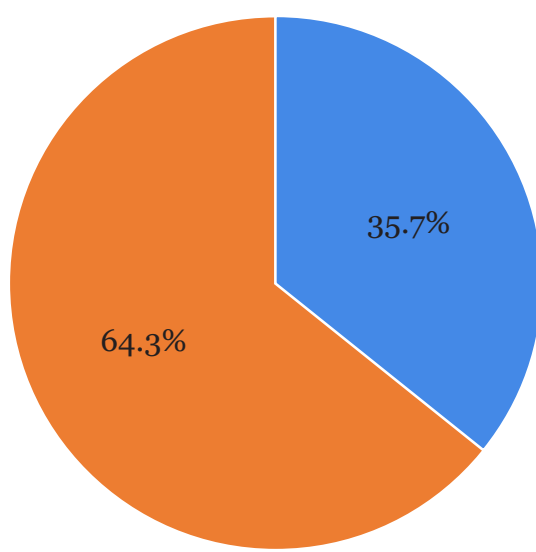

Abused

Not abused

Figure 1. General prevalence of CSA among respondents total of 21 respondents that experienced CSA with penetration, $8(38.1 \%)$ of the respondents experienced forced vaginal intercourse.

Table 3 summarises the pattern of CSA among the respondents. Majority of the perpetrators were neighbours (34 [29.3\%]), family member/boyfriend/girlfriend (20 [17.2\%]) each and strangers (17 [14.7\%]). Most of the respondents (62 [53.4\%]) were abused between ages of 12 and 18 years old. Home (33.6\%) was noted as the commonest place of abuse. While a higher proportion of the respondents experienced sexual abuse only once (68.1\%) and still felt bad about the incident, (75 [64.5\%]), a small proportion were still experiencing the abuse, (15 [12.9\%]). Only 1.5\% of the respondents reported sexual abuse to the authorities.

Figure 2 reveals the identity of the abuser. Neighbours were found to be the commonest sexual abuser of children (34 [29.3\%]).

Table 2. Prevalence of CSA among the respondents

CSA without physical contact $(n=50)$

Forced to look at the genitalia

$10(20)$

Forced to show naked body

Forced to watch pornography

Pictures of nude body taken against will

Shared pictures of self to others against will

CSA with physical contact but without penetration $(n=45)$

Touched against will with sexual intention

$10(22.2)$

Forced to kiss someone

Forced penetration with finger, someone tried to but did not succeed

Forced vaginal intercourse against will, someone tried but did not succeed

Forced anal intercourse, someone tried to but did not succeed

Forced oral intercourse, someone tried to but did not succeed

$5(11.1)$

Forced into prostitution

CSA with penetration $(n=21)$

Forced penetration with finger or object

Forced vaginal intercourse

$8(38.1)$

Forced anal intercourse

$3(14.3)$

Forced oral intercourse 
Table 3. Pattern of CSA among the respondents

\begin{tabular}{|c|c|c|}
\hline Variables & Descriptions & $N(\%)$ \\
\hline \multirow[t]{7}{*}{ Identity of abuser } & Parent & $9(7.8)$ \\
\hline & Family member & $20(17.2)$ \\
\hline & Boyfriend/Girlfriend & $20(17.2)$ \\
\hline & Teacher & $7(6.0)$ \\
\hline & Neighbour & $34(29.3)$ \\
\hline & Stranger & $17(14.7)$ \\
\hline & Others & $9(7.8)$ \\
\hline \multirow[t]{3}{*}{ Age at first abuse } & 1-6 years old & $234(72.0)$ \\
\hline & 7-11 years old & 42 (12.9) \\
\hline & 12-18years old & $49(15.1)$ \\
\hline \multirow[t]{5}{*}{ Place where event occurred } & At home & $39(3.6)$ \\
\hline & At another home & $30(25.9)$ \\
\hline & At school & $14(12.1)$ \\
\hline & At public place & $18(15.5)$ \\
\hline & Others & $15(12.9)$ \\
\hline \multirow[t]{4}{*}{ Frequency of occurrence } & Once & $79(68.1)$ \\
\hline & $2-5$ times & $27(23.3)$ \\
\hline & $6-10$ times & $5(4 \cdot 3)$ \\
\hline & More than 10 times & $5(4 \cdot 3)$ \\
\hline \multirow[t]{2}{*}{ Still experiencing abuse } & Yes & $15(12.9)$ \\
\hline & No & $101(87.1)$ \\
\hline \multirow[t]{2}{*}{ Still feel bad about the incident } & Yes & $75(64.7)$ \\
\hline & No & $41(35 \cdot 3)$ \\
\hline \multirow[t]{2}{*}{ Reported to the authorities } & Yes & $15(1.5)$ \\
\hline & No & $101(98.5)$ \\
\hline
\end{tabular}

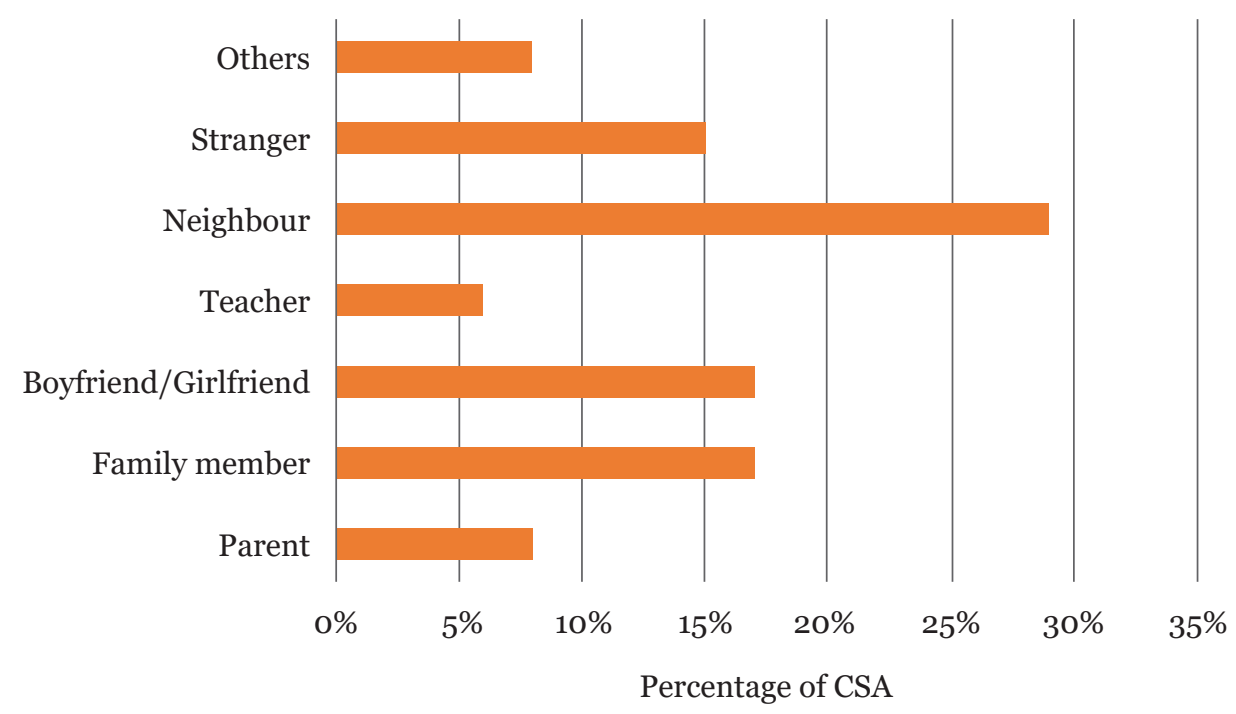

Figure 2. The identity of the CSA 
Original Article | Predictors of child sexual abuse in Enugu, Nigeria

Figure 3 shows that 39 (33.6\%) CSA was most likely to occur at home.

Table 4 highlights the crude odds ratio estimate. Here, grouped ages, class of students, father's occupation, mother's and father's education were noted to be individual factors that were associated with CSA. These variables were statistically significant at $P$-value of 0.05 .
Table 5 highlights the results from logistic regression analysis. It reveals that the father's education and class level of the students were significant predictors of CSA. Adolescents in SSS2 were 2.5 times more likely to experience sexual abuse than those in other classes. Fathers who had obtained at least a secondary education were 5 times more likely to have sexually abused children than other children. This result was found to be statistically significant.

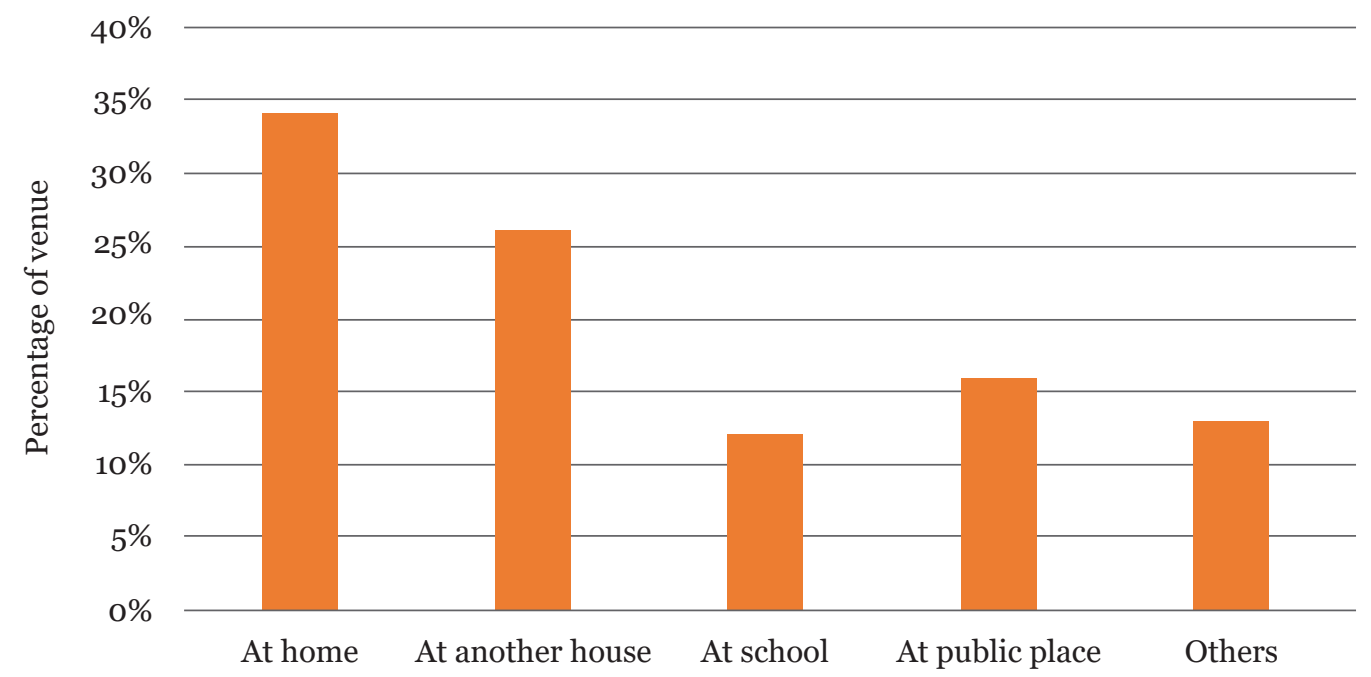

Figure 3. Common venues of CSA

Table 4. Bivariate analysis of CSA among the respondents

\begin{tabular}{|c|c|c|c|c|}
\hline Variables & $\begin{array}{c}\text { Yes } \\
(n=116)\end{array}$ & $\begin{array}{c}\text { No } \\
(n=209)\end{array}$ & $\begin{array}{c}\text { Chi-squared } \\
\left(\chi^{2}\right)\end{array}$ & $P$-value \\
\hline \multicolumn{5}{|l|}{ Gender } \\
\hline Male & $46(39.7)$ & $101(48.3)$ & 2.264 & 0.132 \\
\hline Female & $70(60.3)$ & $108(51.7)$ & & \\
\hline \multicolumn{5}{|c|}{ Age group (years old) } \\
\hline $11-13$ & $5(4 \cdot 3))$ & $23(11.0)$ & 11.109 & $0.004^{*}$ \\
\hline $14-16$ & $95(81.9)$ & $135(64.6)$ & & \\
\hline $17-19$ & $16(13.8)$ & $51(24.4)$ & & \\
\hline \multicolumn{5}{|l|}{ Class } \\
\hline $\mathrm{SSS} 1$ & $8(6.9)$ & $78(37.3)$ & 61.203 & $<0.001^{*}$ \\
\hline $\mathrm{SSS} 2$ & $100(86.2)$ & $87(41.6)$ & & \\
\hline SSS3 & $8(6.9)$ & $44(21.1)$ & & \\
\hline \multicolumn{5}{|l|}{ Tribe } \\
\hline Igbo & $111(95.7)$ & $195(93.3)$ & 0.773 & 0.379 \\
\hline Others & $5(4.3)$ & $14(6.7)$ & & \\
\hline
\end{tabular}


Table 4. (continued)

\begin{tabular}{|c|c|c|c|c|}
\hline Variables & $\begin{array}{c}\text { Yes } \\
(n=116)\end{array}$ & $\begin{array}{c}\text { No } \\
(n=209)\end{array}$ & $\begin{array}{c}\text { Chi-squared } \\
\left(\chi^{2}\right)\end{array}$ & $P$-value \\
\hline \multicolumn{5}{|l|}{ Who they live with } \\
\hline Non-relatives & $4(3.4)$ & $16(7.7)$ & 2.286 & 0.131 \\
\hline Parents/Relatives & $112(96.6)$ & $193(92.3)$ & & \\
\hline \multicolumn{5}{|l|}{ Mother's education } \\
\hline Primary education and below & $9(7.8)$ & $49(23.4)$ & 12.520 & $<0.001^{*}$ \\
\hline Secondary and above & $107(92.2)$ & $160(76.6)$ & & \\
\hline \multicolumn{5}{|l|}{ Father's education } \\
\hline Primary education and below & $7(6.0)$ & $55(26.3)$ & 19.876 & $<0.001^{*}$ \\
\hline Secondary education and above & $109(94.0)$ & $154(73.7)$ & & \\
\hline \multicolumn{5}{|l|}{ Mother's occupation } \\
\hline Unemployed & $4(3.4)$ & $14(6.7)$ & 1.506 & 0.220 \\
\hline Employed & $112(96.6)$ & $195(93 \cdot 3)$ & & \\
\hline \multicolumn{5}{|l|}{ Father's occupation } \\
\hline Unemployed & $9(7.8)$ & $33(15.8)$ & 4.275 & $0.039^{*}$ \\
\hline Employed & $107(92.2)$ & $176(84.2)$ & & \\
\hline
\end{tabular}

Note: *Signifies significant variables entered into logistic regression

Table 5. Predictors of CSA among the respondents

\begin{tabular}{lccc} 
Variables & Wald & P-value & $\begin{array}{c}\text { AOR (95\% CI on } \\
\text { multivariate analysis) }\end{array}$ \\
$\begin{array}{l}\text { Sex (female) } \\
\text { Class }\end{array}$ & 1.378 & 0.240 & $1.401(0.798-2.459)$ \\
$\quad$ SSS1 & 46.243 & $<0.001$ & 1 \\
$\quad$ SSS2 & 2.297 & 0.130 & $2.482(0.766-8.045)$ \\
SSS3 & 13.997 & $<0.001$ & $0.181(0.074-0.444)$ \\
Graded age (years old) & & & 1 \\
$\quad 11-13$ & 1.589 & 0.452 & $0.653(0.156-2.736)$ \\
$\quad 14-16$ & 0.341 & 0.559 & $0.613(0.286-1.312)$ \\
$\quad 17-19$ & 1.589 & 0.207 & $1.643(0.649-4.159)$ \\
Mother's education (secondary and above) & 1.097 & 0.295 & $5.264(2.035-13.618)$ \\
Father's education (secondary and above) & 11.728 & 0.001 & $2.126(0.877-5.150)$ \\
Father's occupation (employed) & 2.790 & 0.095 & $2.819(0.802-9.902)$ \\
Living with relatives & 2.612 & 0.106 & \\
\hline
\end{tabular}

Notes: AOR = adjusted odds ratio; $P$-value of 0.2 was used as a cut-off point from which variables were moved from bivariate into multivariate analysis 


\section{Discussion}

The prevalence of CSA in our study was high (35.7\%). This was similar with reports from other studies done in South-East Nigeria, South-South Nigeria, North-East Nigeria and Switzerland where the prevalence rates were $40 \%, 36.7 \%, 36 \%$ and $35.1 \%$, respectively (14, 33-35). In contrast, a much lower prevalence rate at $0.06 \%, 0.4 \%$ and $1.6 \%$ were found in studies done in North-West Nigeria, Senegal and South Africa, respectively $(15,36,37)$. This low prevalence rates can be attributed to different methodologies like the study area and the age of the study population $(33,38)$. Also in contrast, a higher prevalence rate of $69.9 \%$ and $77 \%$ were found in studies done in different parts of Nigeria though this was done among adolescents who were street hawkers and girls in paid employment $(25,39)$. This various discrepancies in the prevalence rates may be attributed to social and cultural variations found across different geographical zones in the world which can exhibit positive differences in incidence or are affected by how the disclosure and reporting of cases are understood in various cultures $(33,39)$. The Child Right Act of Nigeria enacted in 2003 provides the protection of children from CSA and carries a sentence of life imprisonment if the sexual offender is convicted. However, in 2015 the Violence Against Persons (Prohibition) Act was established and consisted of various levels of punishment ranging from life imprisonment to a minimum sentence of 12 years imprisonment depending on the type of sexual violence (40). However, this law has not been fully implemented. Educational programmes should be provided to parents and the community at large by the government. Child right advocates and practitioners must rise up and expound on the dangers of non-reporting of CSA as this may send a wrong signal to perpetrators to continue to abuse children (40).

In our study, females (60.3\%) were more sexually abused than males. This was similar to findings from studies done among female students in Zaria, Nigeria and Ghana where over $80 \%$ of the victims were females $(41,42)$. Studies carried out among university and high school students in Tanzania and Turkey were in concordance with our study that most of the victims were females at $31 \%$ and $13.4 \%$, respectively $(43,44)$. This could be due to the fact that females are more vulnerable to sexual abuse because they are usually being used as domestic servants and victims of child labour (42). Another reason may be because females exhibit early sexual maturation compared to males and these physical features make them appear attractive, more vulnerable to unwanted advances, seduction by older and more experienced males (45). Males, on the other hand, are believed to contribute to this as it is known in the African setting due to their male ego, they hardly mention that they were sexually abused unlike females (46). In contrast, studies done in Saudi Arabia among secondary school students showed that sexual abuse occurred more in boys than girls $(39,47)$. However, study done in Lebanon among secondary school students showed no gender difference (48). This low prevalence of CSA among girls in Arab countries when compared to boys was attributed to their religion, cultural norms and values where girls are not allowed to go outside unattended making it difficult for them to be exposed to extra-familial perpetration though this does not affect the familial perpetration which is responsible for the majority of the CSA recorded in the Arab countries (49).

The commonest form of abuse was been forced to watch pornography (40\%). Likewise a study done among secondary school students in Rivers State, Nigeria supports our findings that the most common form of abuse $(32.4 \%)$ was watching pornographic materials like pictures, drawings, video tapes or magazines (33). In contrast, studies done in Ethiopia, Malawi, Nepal and Switzerland among adolescents showed that the most prevalent form of sexual abuse were verbal sexual harassment (32.2\%), child been fondled (87.7\%), the use of vulgar words (66.7\%) and sexual harassment via internet (37.9\%), respectively $(35,50-52)$. Pornography was found to be common in our study maybe because we are in the era of advanced technological knowhow which gives gullible adolescents easy access to the social media through the internet of things bringing the perpetrators of this crime close enough to deceive or lure their victims. Pornography is known to cause sexual arousal for perpetrators but there are no reports supporting if it would make them act on this arousal but it seems to be part of the constellation about what can cause them to abuse adolescents (33).

Majority (29.3\%) of our victims reported neighbours as their main perpetrators. This is similar to a research carried out among adolescents in Ethiopia (16\%), Tanzania (> 30\%), Egypt (44.8\%) and Singapore which showed 
that most of their perpetrators were neighbours $(53,56)$. In contrast a study done in South-East Nigeria among adolescents, they identified family members and relatives (63.8\%) as the most common perpetrators (14). Likewise, a study done in Port Harcourt shows that majority of the perpetrators were caregivers/family relatives (33.8\%) (33). Strangers however were pointed out as the main perpetrators in reports from some Asian countries notably Bangladesh and Japan (57). Furthermore, a study conducted in South Korea reported peers as majority (20.7\%) of the perpetrators in all research cases (58). This discrepancy may be due to environmental or cultural factors or both influencing the perpetration of CSA (15). However, the familiarity between the perpetrator and its victim makes suspicion of sexual abuse by parents or passer-by difficult to detect (46). This is common among children who were abused by family members and tend to withhold information regarding to their family members (45). Most of the sexually abused adolescents do not tell anyone about their sexual abuse even when asked by parents or any other higher authority (45). When a family member is a perpetrator, the victims are afraid to disclose the news because they are usually threatened or they believe that it will hurt their parents or that they may not be believed. However, they are more willing to talk about perpetrators outside their family and seek justice (45).

The home was the commonest place of abuse in our study (33.6\%). This is consistent with a study done among secondary school children in India showing that majority (53\%) of adolescents were sexually abused at home (59). In contrast, a study done in Vietnam among school age children considered schools as the main place of abuse (60). Also, studies done in Egypt (48.9\%), Nepal (81\%) and in the rural area of Northern Cape, South Africa (81.6\%) revealed that majority of their victims were sexually abused in a public place and this finding was attributed to the use of drugs especially in Northern Cape $(52,61,62)$. A similar study conducted in a South-West Nigeria showed that the place of abuse had an even spread among homes, schools, neighbours' house and others (15). A study done on CSA in sub-Saharan Africa corroborates the fact that children can be sexually abused and exploited in a variety of settings (63). Survey done in the United Kingdom revealed that the home which should be a safe place appears to be the most dangerous place for children (64).
Majority of the adolescents were sexually abused once. This was similar to a study done in South-West Nigeria where $67.8 \%$ of all cases of CSA occurred only once (15). Another study done in Malawi among female students showed that $76.6 \%$ were not regularly abused while 21.0\% indicated they were regularly abused (51). A similar study done in Nepal supports our finding as $76.2 \%$ of the victims experienced sexual abuse once while 19.0\% experienced it frequently (52). Reason for this is not clear but believed to be because the perpetrator may act on impulsively when an opportunity presents itself and decides afterwards not to repeat that act as they usually prey on easy targets and other vulnerable victims to minimise chances of exposure (15). Under-reporting of CSA by the victims can be a contributory factor especially if they were threatened by the perpetrators adding to an overall low frequency of reporting of the occurrence.

Bivariate analysis revealed a significant association between age, class, parental education and father's occupation with the prevalence of CSA. It is important to recognise that in bivariate analysis, $P$-values and crude odds ratio are obtained which have not taken into cognizance, confounding variables. We can only generate predictors from only multivariable analysis (logistic regression) that takes care of variables that may be confounding the true association between an exposure and an outcome.

There was a significant association between age and prevalence of CSA on bivariate analysis. Adolescence is a rapid phase in human development with its biological maturity preceding its psychosocial maturity (65). Since they are still undergoing physical, neurodevelopmental and psychosocial changes, their inquisitiveness and eagerness to experiment new things make them easy target that can be lured by their perpetrators if not duly monitored by parents and guardians (65). It is pertinent that non-governmental organisations, schools, churches or religious leaders should be involved in providing sex education programmes for children to help protect them against sexual predators.

On multivariate logistic regression, class level and father's education were found to be the only significant predictors of CSA since students in SSS2 were 2.5 times more likely to be sexually abused than students in other classes. However, we must state that this may not be a 
true association since the confidence interval for SSS2 crosses one. Students in high senior secondary classes are particularly vulnerable as a result of their ages and the stage of adolescence that they are undergoing and tend to be more adventurous especially in the absence of parental monitoring and supervision. This is made worse by the societal norms, pressures and weak policies that propagate the weak nature and sexual inferiority of the girlchild (10). Students in SSS2 usually have more time than those in SSS1 and SSS3. While students in SSS1 are trying to settle down after undergoing external junior secondary school examinations to get into SSS1, those in $\mathrm{SSS}_{3}$ on the other hand are busy preparing for their senior school certificate examinations as well as their university entrance examinations. There was no other study found to have any similar finding to ours in terms of class level and its association with CSA. More research maybe needed in this area. This study also revealed that a high proportion of the respondents whose parents achieved secondary school education and above were more likely to be sexually abused than others. This finding is in contrast to a study done among female university students in Eastern Ethiopia where achieving secondary school education by the father was associated with low sexual abuse (66). Likewise, respondents whose mothers attained secondary school education and above were more abused than those with primary school education and below. Generally, parents with higher educational qualifications tend to have better employment opportunities as they work outside the family setting, exposing their children to sexual abuse through lack of parental protection and supervision (45). Our study revealed that adolescents whose fathers were self-employed or salaried were more up to five times more likely to be sexually abused. This may be attributed to the fact that such fathers had better employment opportunities and so were away from home (45).

\section{Conclusion}

This study showed a low prevalence of CSA with majority of the perpetrators were neighbours and the sexual abuse occurred mostly at home. The only predictor of the prevalence of CSA was found to be the SSS2 class. Efforts should be made to make sure that the children recognise abusive situations and are able to disclose to authorities who their abusers are. A stable home is important as this helps parents monitor who their children are with at home, including other family members, neighbours and domestic helps since most cases of CSA in our study happened at home. The government should provide public enlightenment on the risk factors and prevention of CSA to help combat its occurrence. Guidance and counseling units, religious groups could play a vital role in putting adolescents through all the available and accessible sex education sources with the aim of improving their reproductive health and making them live a better life. The Education Ministry as well as non-governmental organisations should be involved to help provide adequate resources for implementing education programme for secondary schools in Nigeria.

\section{Limitation of Study}

CSA can be perceived as a taboo especially in Africa. This could have resulted in social desirability bias as the respondents may be reluctant to be fully honest about their actual experiences and the willingness to give correct information thereby underestimating the magnitude of the problem.

\section{Acknowledgements}

We would like to thank the Commissioner of Health, Enugu State, the Principals of the selected schools and the students for their participation in this study.

\section{Conflict of Interest}

None.

\section{Funds}

None.

\section{Authors' Contributions}

Conception and design: CJO

Analysis and interpretation of the data: CJO

Drafting of the article: OHC, NIN, ATJ

Critical revision of the article for important intellectual content: OHC, NIN, ATJ

Final approval of the article: CJO, OHC, ATJ

Provision of study materials and patients: NIN

Statistical expertise: CJO 


\section{Correspondence}

Dr Chinonyelu Jennie Orji

MBBS (UNIPORT), MSc Public Health (USW), FWACP (ESUTHP)

Department of Community Medicine

Enugu State Teaching Hospital

Parklane Enugu.

P.M.B 1030

Enugu State, Nigeria.

Tel: +2348037109273

E-mails: orjichinonyelu@gmail.com, chinonyelu@yahoo.com

\section{References}

1. World Health Organization. Report on the consultation on child abuse prevention (WHO/ HSC/PVI/99.1) [Internet]. Geneva, Switzerland: World Health Organization; 1999 (Retrieved 2019 Nov 1). Available at: http://www.who.int/ mip2001/files/2017/childabuse.pdf

2. Seldak A, Mattenburg J, Basena N, Petta I, McPherson K, Green A, et al. Fourth National Incidence Study (NIS-4) of child abuse and neglect: report to Congress, Washington DC, the US Department of Health and Human Services, Administration for Children and Families; 2010. https://doi.org/10.1037/e565022012-001

3. Ogunfonoka AA, Fajemilebin RB. Impact of a school-based sexual abuse prevention education program on the knowledge and attitude of high school girls. The Journal of School Nursing. 2012;28(6):459-468. https://doi.org/10.1177/ 1059840512446949

4. World Health Organization. Preventing adolescents: a guide to implementing the recommendations of World Report on Adolescents and Health. Geneva, Switzerland: WHO; 2011.

5. Kumar R, Goyal A, Singh P, Bhardwaj A, Mittal A, Yadah SS. Knowledge, attitude and perception of sex education among school going adolescents in Ambala District, Haryana, India: a crosssectional study. J Clin Diagn Res. 2017;11(3). https://doi.org/10.7860/JCDR/2017/19290.9338

6. World Health Organization. Maternal, newborn, child and adolescent health [Internet]. Geneva, Switzerland: World Health Organization; 2020. Available at: www.who.int/maternal_child_ adolescent/topics/adolescence/development/en/
7. UNICEF. Towards an AIDS-free generationchildren and AIDS: sixth stocktaking reports; 2013. New York: UNICEF; 2013.

8. UNICEF. The state of the world's children: adolescence, an age of opportunity. New York: UNICEF; 2011.

9. Meinek S, Cluver LD, Boyes ME. Longitudinal predictors of child sexual abuse in a large community-based sample of South African Youth. $J$ Interpers Violence. 2017;32:2804-2836. https://doi.org/10.1177/o886260515596331

10. Akanle F, Asebiomo A. Sexual abuse among female secondary school students and social cultural issues that hinder or enhance responses to child sexual abuse in Africa. IPEDR. 2012;56:17.

11. Leach F, Machakanja P, Mandoga J. Preliminary investigation into the abuse of girls in Zimbabwean Junior secondary schools. Education Research Papers 12839. UK: Department of Int. Development; 2000.

12. Abdulkadir I, Umar LW, Musa HH. Child sexual abuse; review of cases seen at General Hospital, Suleja, Niger State. Annals of Nigerian Medicine. 2011;5:15-19. https://doi.org/10.4103/o331-3131 .84223

13. Terry KJ, Lalor K. Child sexual abuse in subSaharan Africa: a literature review. Child Abuse and Neglect. 2004;28:439-460. https://doi.org/ 10.1016/j.chiabu.2003.07.005

14. Manyike PC, Chinawa JM, Aniwada E, Odutola OI, Chinawa TA. Child sexual abuse amomg adolescents in southeast Nigeria: a concealed public health behavioural issue. Pak $\mathrm{J} \mathrm{Med} \mathrm{Sci.}$ 2015;31(4): 827-832. https://doi.org/10.12669/ pjms.314.7115

15. David N, Ezechi O, Wapmuk A, Gbajabiamila T, Ohihoin A, Herbertson E, et al. Child sexual abuse and disclosure in South-West Nigeria: a community based study. Afri Health Sci. 2018;18(2):99-208. https://doi.org/4314/ahs. v18i2.2

16. Lalor K. Child sexual abuse and HIV transmission in sub-saharan Africa. Child Abuse Rev. 2008;17(2):94-107. https://doi.org/10.1002/car .1020 
17. Ogunyemi O. Knowledge and perception of child abuse in urban Nigeria: some evidence from a community-based project. Reprod Health. 2000;4(2):44-53. https://doi.org/10 $.2307 / 3583447$

18. Watts G, Zimmeran C. Violence against women: global scope and magnitude. LANCET. 2002;359:1232-1237. https://doi.org/10.1016/ So140-6736(02)08221-1

19. Olley BO. Child sexual abuse, harmful alcohol use and age as determinants of sexual risky behaviours among freshmen in a Nigerian university. Afr J Reprod Health. 2008;12(2):7588.

20. Pereda N, Guilera G, Forns M, Gomez-Benito J. The prevalence of child sexual abuse in community and student samples: a metaanalysis. Clin Psychol Rev. 2009;29:328-338. https://doi.org/10.1016/j.cpr2009.02.007

21. World Health Organization. Child maltreatment [Internet]. Geneva, Switzerland: World Health Organization; 2020 [Retrieved 2020 Jun 20). Available at: https://www.who.int/en/news -room/factsheets/detail/child-maltreatment

22. Barth J, Bermetz L, Herin E, Trelle S, Tonia T. The current prevalence of child sexual worldwide: a systematic review and meta-analysis. Int $J$ Public Health. 2015;58(3):469-483. https://doi .org/10.1007/s00038-012-0426-1

23. Odu B, Falana BA, Olotu OA. Prevalence of violent sexual assault on South-west Nigerian girls. Euro Scientific J. 2014;10(7):471-481.

24. Odeyemi KA, Onajole AT, Ogunnowo BE. Sexual behaviour and the influencing factors among out of school female adolescents in Mushin market, Lagos, Nigeria. Int $J$ Adolesc Med Health. 2009;21(1):101-109. https://doi.org/10.1515/ IJAMH.2009.21.1.101

25. Ikechebelu JI, Udigwe GO, Ezechukwu CC, Ndinechi AG, Joe-Ikechebelu NN. Sexual abuse among juvenile female street hawkers in Anambra State, Nigeria. Afr $J$ Reproductive Health. 2009;12(2):111-119.

26. World Health Organization. Guidelines for medico-legal care for victims of sexual violence [Internet]. Geneva, Switzerland: World Health Organization; 2003 [Retrieved 2019 Dec 14]. Available at https://apps.who.int/iris/handle/ $10665 / 42788$
27. Yahaya I, Soares J, Pons De Leon A, Macassa G. Comparative study of the socioeconomic factors associated with child sexual abuse in sub-Saharan Africa. Pan Afr Med J. 2012;11:51.

28. Eze BU, Merit TI. The controls of household mobility in Enugu Metropolitan Area, Nigeria. Int J Soc Sci Hum Inven. 2019;6:5221-5224.

29. Iyoke C.A, Onah H.E, Onwasigwe C.N. Teachers ` Attitude is not an impediment to adolescent sexuality education in Enugu, Nigeria. Afr $J$ Reproductive Health. 2006;10(1):81-90. https://doi.org/10.2307/30032447

30. Araoye MO. Research methodology with statistics for health and social scienced. 1st ed. Nathadex: Ilorin; 2004. p 120.

31. Ohayi RS, Ezugwu CE, Chigbu C, Arinze-Onyia SU, Iyoke CA. Prevalence and pattern of rape among girls and women attending Enugu State University Teaching Hospital. Int $J$ Gynecol Obstet. 2015;130(1):10-13. https://doi.org/10 $.1016 /$ j.ijgo.2015.02.017

32. Babbie E, Mouton J. The practice of social research. Cape Town: Oxford University Press Southern Africa; 2005.

33. Okagua J, Alex-Hart BA. Sexual abuse amongst secondary school students in Port Harcourt, South-South Nigeria: a rising public health menace, factors and implications. Acta Scientific Paediatrics. 2020;3:47-52. https://doi.org/10 $.31080 /$ ASPE.2020.03.0224

34. Ajuwon AJ, Olaleye A, Faromoju B, Ladipo O. Sexual behaviour and experience of sexual coertion among secondary school students in three states in North Eastern Nigeria. BMC Public Health. 2006;6:310. https://doi.org/ 10.1186/1471-2458-6-310

35. Meichum MK. Child sexual abuse revited: a population-based cross-sectional study among Swiss adolescents. $J$ Adolesc Health Care. 2014;54:304-311. https://doi.org/10.1016/j :jadohealth.2013.08.020

36. Faye Dieme ME, Traore AL, Giueye SM, Moreira PM. Sexual abuse: epidemiological, clinical aspects and management at gynaecological and obstetrical department of Dakar University Hospital. $J$ Gynecol Obstet Biol Reprod. 2008;37(4):358-364. https://doi.org/10.1016j :jgyn.2007.11.002 
37. Jewkes R, Levin J, Mbananga N. Rape of girls in South Africa. LANCET. 2002;359:319-320.

38. Gabrie-Job N, Alikor EAD, Akari NA. Prevalence of chid sexual abuse among secondary school adolescents in Obio/Akpor local government area, Nigeria. Nige J Psediatr. 2019;46(4):156-162.

39. Audu B, Geidan A, Jarma H. Child labour and sexual assult among girls in Maidugiri Nigeria. Int $J$ Gynaecol Obstetrics. 2009;104:64-67. https://doi.org/10.1016/j.ijgo.2008.09.007

40. Akpoghome TU. Analysis of the domestic legal framework on sexual violence in Nigeria. $J$ Law Crim Justice. 2016;4(2):17-30. https://doi.org/ 1015640/jlcj.v4n2a3

41. Bugaje M, Ogunrinde G, Frank J. Child sexual abuse in Zaria, Nort-Western Nigeria. Niger $J$ Paediatrics. 2012;39(3):110-114. https://doi .org/10.4314/njp.v39i3.4

42. Agu AO, Brown CK, Adamu-Isaah M, Duncan BA. Perspectives of sexual abuse of school children in basic and secondary schools in Ghana. Afr J Crim Just Studies. 2018;11.

43. McCrann D, Lalor K, Kataboro JK. Childhood sexual abuse among university students in Tanzania. Child Abuse Ngl. 2006;30:1343-1351. https://doi.org/10.1016/j.chiabu.2006.05.009

44. Alikasifoglu M, Erginoz E, Ercan O, Deniz AD, Uysal O, Ilter O. Sexual abuse among female high school students in Istanbul, Turkey. Child Abuse Negl. 2006;30:247-255. https://doi.org/ 10.1016/j.chiabu.2005.10.012

45. Akinsulire OO. A comparative study on prevalence, pattern and determinants of sexual abuse amongst adolescents in selected slum and non-slum communities in Lagos State. PhD diss. Lagos, Nigeria: Lagos State University; 2017. pp 104-115

46. Balogun FM, Adenowuso OE. Prevalence and pattern of child sexual abuse: a cross-sectional study among male secondary school adolescents in Ibadan, Nigeria. $J$ Child Adolesc Health. 2020;4:1-8.

47. Aleissa M, Saleheen H, Al-Wallan N, AlKashan $\mathrm{M}$, AlSubaie $\mathrm{N}$, Almuneef $\mathrm{M}$. Prevalence of sexual abuse among secondary school students in Saudi Arabia. Violence Vict. 2018;33:855-870. https://doi.org/10.1891/o886-6708.VV-D-17-00018
48. Usta J, Farver J. Child sexual abuse in Lebanon during war and peace. Child Care Health Dev. 2010;36:361-368. https://doi.org/10.1111/j.1365 $-2214.2010 .01082 . x$

49. Beier KM. Preventing child sexual abuse the prevention project Dunkelfeld. J Sex Med. 2018;15:1065-1066. https://doi.org/10.1016/j :jsxm.2018.03.008

50. Bekele I, Zewde W, Neme A. Assessments of prevalence, types and factors associated with associated sexual abuse in high school in Limmu Gnet High School. Health Sci J. 2017;11:3. https://doi.org/10.21767/1791-809X.1000506

51. Dzimadzi R, Klopper H. Knowledge of sexual abuse amongst female students in Malawi. Curationis. 2007;30(3):23-30. https://doi.org/ 10.4102/curationis.v30i3.1094

52. Sharma A, Magar KR. Awareness of sexual abuse adolescents in Bagheng district of Nepal. Janapriya Journal of Interdisciplinary Studies. 2018;7:14-20. https://doi.org/10.3126/jjis.v7i1 .23046

53. Worku D, Gebremanam A, Jayalakshim S. Child sexual abuse and its outcomes among high school students in Southweat Ethiopia. Trop Doc. 2006;36:137-140. https://doi.org/10.1258/ o049475067777978325

54. Kisanga F, Urassa D, Hogan N, Mbwambo J. Child sexual abuse and possible health consequences among secondary school students in urban Tanzania. Med J. 2015;6:46-53. https://doi.org/10.1016/j.ejfs.2012.05.001

55. El-SAyed Aboul-Hagag K, Hamed AF. Prevalence and pattern of CSA reported by cross sectional study among the university students Sonog University, Egypt. Egyptian Journal of Forensic Sciences. 2012;2:89-96.

56. Back SE, Jackson JL, Fitzgerald M, Shaffer A, Salstrom S, Osman MM. Child sexual and physical abuse among college students in Singapore and United States. Child Abus Negl. 2003;27:1259-1275. https://doi.org/10.1016/j .chiabu.2003.06.001

57. Terry KJ, Tallon J. Child sexual abuse: a review of the literature [Internet]. New York, United States: Office of Justice Programs; 2004 [Retrieved 2019 Nov 10]. Available at: http://www.usccb .org/nrb/johnjaystudy/litreview 
Original Article | Predictors of child sexual abuse in Enugu, Nigeria

58. Choi KS, Choo K, Choi J, Woo Y. Understanding the dynamics of the victim-perpetrator relationship in child sexual abuse: an examination of child sex abuse victimization data in South Korea. J Criminol. 2015;10:79-97. https://doi .org/10.1007/s11417-015-9202-5

59. Jasmine K, Hameed A. Child abuse awareness among higher secondary school students. $J$ Res Method Edu. 2016;6(4):75-79.

6o. Do HN, Nguyen HQT, Nguyen LTT, Nguyen HD, Bui TP, Phan NT et al. Perception and attitude about child sexual abuse among Vietnamese school-age children. Int $J$ Environ Res Public Health. 2019;16(20):3973. https://doi.org/10 $.3390 /$ ijerph16203973

61. Desouky DES, Marawan H. Awareness and experience of sexual harrassment among Menoufiya University students. Asia $J$ Public Health. 2013;4:16-26.

62. Fouche JM. Adolescents knowledge and awareness regarding sexual abuse in a rural area of the Northern Cape [PhD diss]. Northwest University South Africa, Potchefstroom Campus; 2015 .
63. Lalor K. Child sexual abuse in sub-Saharan Africa: a literature review. Child Abuse and Neglect. 2004;28:439-46o. https://doi.org/10.1016/j .chiabu.2003.07.005

64. Daley W. Fearing wrong why what doesn't scare us should [Internet]. Uxbridge, Middlesex, UK: World Vision Int./Ipsos Reid: 2014. p 43 [Retrieved 2019 Dec 15]. Available at: http://www.wvi.org/fearingwrong

65. World Health Organization. Adolescent health and development [Internet]. Geneva, Switzerland: World Health Organization; 2020 [Retrieved 2020 Oct 30]. Available at: https://www.who .int/news-room/q-a-detail/adolescent-health-and -development

66. Bekele T, Deressa W. Experience of sexual coercion and associated factors among female students of Ambo University in Ethiopia. Sci $J$ Public Health. 2014;2:532-538. https://doi.org/ $10.1155 / 2014 / 417517$ 